\title{
Cryptocurrencies in the global space: factors and prospects of promotion
}

\author{
Anna Kramarenko ${ }^{* 1}$, Anton Kvitka ${ }^{1}$, Vitaliy Diachek ${ }^{1}$, and Denis Davydov ${ }^{1}$ \\ ${ }^{1}$ V. N. Karazin Kharkiv National University, 4 Svobody Sq., Kharkiv, 61022, Ukraine
}

\begin{abstract}
The article considers the place of cryptocurrency markets in the global economy. The key risks of active implementation of IT achievements in the financial sector were defined. It was shown that cryptocurrencies are associated with settlement operations, investment activities and speculation in the currency markets. It was argued that the availability of equipment for the production of digital currencies, the spread of trust on the part of users and business representatives contribute to the promotion of cryptocurrencies and the penetration of digital currencies in various spheres of economic activity. The attraction of additional resources in the economy in the conditions of insignificant costs for entering the cryptocurrency market that become a factor in the spread of cryptocurrency assets was considered.
\end{abstract}

\section{Introduction}

Cash flow management, effective fundraising, optimization of the tax burden, promotion of products by channels convenient for consumers are issues of concern to representatives of wide business circles. Besides, the creation and implementation of technological innovations at the present stage is the basis of the success of any company. The desire of enterprises to gain and maintain their market share requires significant efforts both in the promotion of existing products and in innovation, for example in the development of new products and updating existing products [1]. In this regard, the creation of technological innovations, the growth of business and the development of entrepreneurial activity are trends that mutually reinforce each other. The increase in the influence of information technology and entrepreneurial activity contributes to the modification of other areas of economic activity.

In particular, the rapid development of information technologies (IT) causes a radical transformation of the financial systems of most countries. At the same time, the most significant changes are observed at the level of financial infrastructure, primarily in the banking system and the foreign exchange market. One of the key risks of active implementation of IT achievements in the financial sector is the possible disappearance of the banking system in the "classical" form or its radical transformation due to the inability to compete with new technologies [2].

\footnotetext{
*Corresponding author: a.o.kramarenko@karazin.ua
} 
At the same time, the most potentially dangerous for classical banks are two technologies - credit electronic platforms and blockchain. Even 3-4 years ago, the companies of credit electronic platforms looked like experimenters, but today the pioneers of this market "Landing Club", "Prosper" and others have a billion capitalization [3]. These companies independently determine the solvency of a person or enterprise using a huge database. After determining the level of solvency of a potential borrower, the electronic platform is looking for an investor. Thus, there is a partial replacement of the financial sector with resources of information technologies and services.

On the other hand, blockchain - a technology of storage and instant transmission of huge amounts of data in encrypted form - is becoming widely used. Blockchain allows anybody to easily manage personal accounts and transfers without the help of a bank. The system has multi-level protection, and most importantly - the corresponding code is seen by all participants in transactions, therefore potentially stolen funds can be observed in the network, so it is impossible to use them criminally. From a technical point of view, blockchain is a technology of distributed registers, which allows anybody to create a decentralized system of relations, in which each next transaction depends on the previous one. Therefore, the transaction data cannot be changed or deleted. For the first time, this term appeared to refer to a distributed database implemented in Bitcoin - the most popular cryptocurrency in the world [2]. It is the emergence of digital currencies, such as Bitcoin, which perform all the functions of money and which, thanks to the blockchain system, have a high degree of protection and security, contributed not only to the change in the functioning of the financial system but also to the modification of the principles of entrepreneurial activity.

\section{Results}

The user can buy Bitcoin or other types of cryptocurrencies, or generate them in the process of mining (the use of computing resources to perform a mathematical task to verify and implement cryptocurrency transactions with the help of special equipment - miners). The cost of the most popular miner produced by the Chinese company "Bitmain", which today occupies $75 \%$ of the world market, is about USD 2,000, and the payback period is about 12 months [4]. Bitcoin is not tied to defined national currencies or assets, and its value is not backed by anything other than the trust of its owners. Bitcoin exchange rate is set on virtual exchanges, where it is exchanged for real money. Digital exchange of cryptocurrencies is carried out on such world exchanges as "Bitfinex", "Poloniex", "Kraken", "Shapeshift", "Changelly", CHBTC, "Bitquare", "Bittrex", "BitMEX", BTER, "Yobit", "CoinExchange", "LiteBit", "Btc Markets" and others [5]. Online rates of different cryptocurrencies can be tracked [6]. The availability of equipment for the production of digital currencies, the spread of trust on the part of users and business representatives, the ability to exchange for real money without significant expenditure of time and resources, the possibility of operational monitoring and a high level of security - all this conditions increase the popularity of these types of assets.

Due to the demand for |fair money" in the world, complete anonymity and protection from counterfeiting, interest in cryptocurrencies is growing rapidly. The anonymity of payments makes the Bitcoin system attractive in a criminal environment [7]. Cryptocurrency is a convenient tool for money laundering, as this type of asset gives relative anonymity to the owner of the currency (the system does not require personal information about the user and his location). This feature minimizes the ability of law enforcement agencies to track criminal activity and identify the offender.

Also, foreign exchange transactions are out of state control, so any transactions with cryptocurrency do not need to be checked by third parties, such as a bank, government 
agency or non-governmental organization. In addition, the user can have more than one account and conduct transactions from different locations at the same time. Bitcoin allows for various money laundering schemes, which virtually blocks the possibility of identifying criminals. The mentioned characteristics of the cryptocurrency encourage legislators around the world to unify the legal system for the use of cryptocurrency as a means of payment [8]. The main attention is paid to the taxation of cryptocurrency turnover. Cryptocurrencies are associated with settlement operations, investment activities and speculation in the currency markets. All these operations have signs of objects of taxation. In this regard, the issues of monitoring the turnover of cryptocurrencies, the definition of the legal framework and economic instruments of taxation and tax control become relevant. To solve these issues, it is necessary to allocate groups of transactions with cryptocurrency, which can be an object of taxation. Attempt to create a similar classification was carried out by Volosych S. and Barannik Yu. It is presented in the figure below.

GROUPS OF CRYPTOCURRENCY TRANSACTIONS

\begin{tabular}{|c|c|c|}
\hline $\begin{array}{l}\text { Cryptocurrency receipt } \\
\text { transactions }\end{array}$ & $\begin{array}{c}\text { Cryptocurrency revaluation } \\
\text { transactions }\end{array}$ & $\begin{array}{l}\text { Cryptocurrency use } \\
\text { transactions }\end{array}$ \\
\hline Purchase & $\begin{array}{l}\text { Revaluation of available } \\
\text { funds for cryptocurrency } \\
\text { wallet }\end{array}$ & Sale \\
\hline $\begin{array}{l}\text { Receipt for goods, } \\
\text { works, services }\end{array}$ & $\begin{array}{l}\text { Closing (reopening) the } \\
\text { cryptocurrency account }\end{array}$ & $\begin{array}{l}\text { Payment for goods, } \\
\text { works, services }\end{array}$ \\
\hline Employer payment for labor & $\begin{array}{c}\text { Cryptocurrency rate change } \\
\text { at the payment date and } \\
\text { at the date of product } \\
\text { recovery }\end{array}$ & Commissions \\
\hline Receiving a gift, etc. & $\begin{array}{l}\text { Tax control } \\
\text { object }\end{array}$ & Gifts, etc. \\
\hline
\end{tabular}

Fig. 1. Cryptocurrency transactions as a tax control object [9]

According to S. Volosych and Yu. Barannik, to prevent the use of cryptocurrencies in terrorist activities, it is advisable to carry out tax control of mining, exchange rate determination transactions, and transactions with cryptocurrencies.

For this purpose, at the macro level, the creation of legal documents regulating the cryptocurrency market should be ensured [9]. The need for structuring the institutional sectors of the economy and activities, which implies the need for a comprehensive study of the processes of differentiation, evolution and economic growth of the total financial potential of the country should be taken into account [10]. Understanding the total financial potential of the country and its timely and qualitative analysis, the choice of the necessary method of assessment and the system of indicators are fundamental for making effective management decisions [11]. At the same time, at the micro level, it is necessary to provide conditions for the identification of owners of electronic wallets, taking into account the importance of strategic management accounting information for strategic management purposes [12]. So, the issues of state regulation of the cryptocurrency market remain open. This situation, on the one hand, poses a threat to the centralized management of economic processes and reduces the number of effective instruments of influence on business entities. On the other hand, such difficulties create opportunities for small and medium-sized enterprises seeking to reduce the tax burden. 
Cryptocurrency exists freely. All sorts of organizations, including those that provide related services, such as a guarantee of safety of coins in the wallet or ensure the security of transactions are trying and will try to adapt to cryptocurrency. Increased competition in the process of saturation of the market, along with increasing innovation and originality of the goods supplied, leads to the development of personal needs. Since entrepreneurs trying to win in tough competition, they are forced to create not only innovative products but also to identify new unique needs [1]. Increasing the level of consumerism against the background of growth in the number of small and medium-sized enterprises contributes to a significant adaptation of cryptocurrency technologies in global markets. Some payment systems accept Bitcoin, such as Visa, Paypal, and Bitpay. For example, the company Bitpay currently serves more than 15,000 business owners and is present in 200 countries [7].

New forms of investment, such as ICO (Initial Coin Offering), are associated with the formation of cryptocurrencies. In simple words, ICO can be compared to cryptocurrency crowdfunding. Most often projects involved in the ICO are somehow connected with the technology of the blockchain and cryptocurrency. By issuing its own "money" and exchanging it for one of the common cryptocurrencies (such as Bitcoin) or even for real currencies, the project can secure the funding needed to launch or develop. In addition, by issuing currency for the project, it is possible to accelerate its development and automatically solve the problem of future monetization [13]. Thus, the presence of significant investment opportunities, a significant level of decentralization, increased consumerism and innovations create favorable conditions for increased adaptation of cryptocurrencies in the business environment.

However, there are risks associated with failures in IT systems caused by various reasons. The need to deepen knowledge about the advantages and disadvantages of electronic payment systems, the need to increase the security of IT technologies and to increase IT literacy slow the development of non-cash payment instruments and, accordingly, limit the growth of cryptocurrency markets.

Representatives of the Central banks note significant risks of cryptocurrency development. Thus, the Head of the Reserve Bank of India said that the virtual currency is a potential financial, operational, legal threat to customers. Cryptocurrencies are vulnerable to hacker attacks, loss of passwords, unauthorized access, and lack of a system for resolving customer complaints [14].

M. Carney talks about the risk of fraud and theft of Bitcoins from the accounts of customers and exchanges. In all cases, the funds were stolen from "hot wallets" when the secret key was stored on a computer or device connected to the Internet [15]. The Head of the Central Bank of Australia believes that cryptocurrencies are of greater interest to criminals than to consumers: "Current fascination with these currencies is more like a speculative mania than using them as an effective and convenient form of electronic payment" [16]. The Vice-Chairman of the National Bank of the Czech Republic said that the rapid changes in purchasing power are a mortal enemy of any good currency [17]. The uniformity of business models of different cryptocurrencies creates the danger of simultaneous changes in the behavior of market players concerning these instruments. Players (miners) have branched virtual communities that use uncontrolled channels of moving money [18]. The high level of volatility in the cryptocurrency market, along with the creation of threats to the stability of the financial system, causes increased interest from investors. A small amount of initial investments and a high level of payback attract an increasing number of entrepreneurs, which in turn contributes to the growth of cryptocurrency markets.

According to Wang Chun Wei, increasing liquidity in the cryptocurrency market contributes to lower liquidity and increase the efficiency of the foreign exchange market [19]. So, the more widespread and developed cryptocurrency technologies are, the more 
stable their functioning is. The level of risk of investments in relevant instruments is reduced on the basis of regulation and increased transparency of market agents.

In this regard, cryptocurrencies are increasingly becoming the focus of investors' attention. Financial indicators in terms of risk and return are different from those of classical financial assets: investments in cryptocurrencies have relatively high volatility, that is, the risk, which, however, is compensated by the high expected return. Also, its low correlation with stock, bond, commodity, and foreign exchange rates creates diversification potential for investors. Investors also do not need to actively manage these assets [20].

Based on the above, it can be argued that cryptocurrencies are not only perceived by the main economic entities as alternative money but also recognized as an object of investment. Profitability expectations and trust positively affect the attitude to these assets. Currency characteristics associated with the expected profitability and compatibility of transactions have a positive impact on the attitude to cryptocurrency [21]. To replace the existing currencies cryptocurrencies lack full recognition from the largest trading platforms and an objective combination with the existing currencies. These factors become an obstacle to the spread of cryptocurrencies in the global space.

Nevertheless, the positive impact on the development of cryptocurrency markets has the fact that the profitability of the cryptocurrency can be predicted based on specific market impulses and the favor of investors [22]. The predictability of changes in market conditions and significant volatility is a significant advantage of cryptocurrencies, which can neutralize the shortcomings associated with the insignificant use of these assets in world trade.

Another opportunity for the growth of the cryptocurrency market is digital financial services (DFS), which can be defined as financial transactions using digital technologies, including electronic money, mobile financial services, online financial services, i-teller and banking without branches, whether banking or non-banking institutions. Digitalization of finance provides an opportunity to achieve broad financial integration by increasing the availability and penetration of digital financial services, benefiting from previously nonbanking sectors of the population and offering digital alternatives to encourage consumers and entrepreneurs to leave the informal sector. DFS also opens up opportunities for the integration of low-income financially isolated groups [23]. The additional resources microentrepreneurs in conditions of the negligible cost of entry into the market of cryptocurrency become a factor of the promotion of cryptocurrencies.

\section{Discussion}

Thus, the spread of cryptocurrencies can affect the level of competition in the financial market and helps to reduce costs, provides an improved experience for entrepreneurs. Nevertheless, attention should be focused on the existence of new risks for consumers in the markets with DFS and cryptocurrencies. Risks such as inadequate disclosure and recovery mechanisms, diversity of suppliers, cross-border sales, arbitration, data protection, lack of coordination between authorities can pose a serious threat to the financial wellbeing of the businesses. These issues require a more detailed study in further studies.

\section{Conclusion}

Based on the presented analysis, the following conclusions and generalizations can be made. Active implementation of IT achievements in the financial sector creates conditions for the restructuring of business processes within the banking system. A factor in 
strengthening this trend is the emergence of digital currencies such as Bitcoin, which perform all the functions of money and which, thanks to the blockchain system, have a high degree of protection and security. The availability of equipment for the production of digital currencies, the spread of trust on the part of users and business representatives contribute to the promotion of these types of assets and the penetration of digital currencies in various spheres of economic activity. This situation, on the one hand, poses a threat to the centralized management of economic processes, and on the other hand, contributes to the possibility of reducing the tax burden on small and medium-sized enterprises. Significant investment opportunities, increased consumerism, and innovation create favorable conditions for increased adaptation of cryptocurrencies in the business environment. At the same time, attraction of additional resources in the economy in the conditions of insignificant costs for entering the cryptocurrency market becomes a factor in the spread of cryptocurrency assets.

\section{References}

1. A. Kvitka, A. Kramarenko, Problems and Perspectives in Management, 2, 42-48 (2018)

2. D. Gladkyh, Bitcoin and other cryptocurrencies: the risks and prospects in Ukraine, available at: http://www.niss.gov.ua/content/articles/files/Glakih_bitcoin-34ba8.pdf (2018) 3. Gref predicted the future, available at: https://utro.ru/articles/2016/11/14/1304545.shtml 4. Are bitcoins legal in Ukraine, available at: https://www.epravda.com.ua/publications/2017/08/11/627993

5. O. Vlasuk, Strategichna panorama, 2, 9-16 (2017)

6. CryptoCurrency Market Capitalizations, available at: https://coinmarketcap.com

7. A. Kvitka, E. Zaytseva, Ekonomichna teoriya ta pravo, 1, 111-119 (2015)

8. V. Dyntu, O. Dykyi, Baltic Journal of Economic Studies, 5 (4), 75-81 (2018)

9. S. Volosovych, Yu. Baraniuk, Banks and Bank Systems, 2 (13) (2018)

10. O. Portna, Actual Problems of Economics, 10 (172), 404- 409 (2015)

11. O. Portna, Actual Problems of Economics, 3(165), 106-112 (2015)

12. M. Bondar, N. Iershova, Baltic Journal of Economic Studies, 1 (1), 47-54 (2015)

13. A. Kvitka, K. Balakleiets, Social economics, 55, 107-114 (2018)

14. R. Gandhi, FinTechs and virtual currency, available at: https://www.bis.org/review/ r170309d.htm (2017)

15. M. Carney, The Future of Money, available at: https://www.bankofengland. co.uk//media/boe/files/speech/2018/the-future-of-money-speech-by-mark-carney (2018)

16. E. Lam, What the World's Central Banks Are Saying About Bitcoin, available at: https://www.bloomberg.com/news/articles/2017-12-15/what-the-world-s-central-banks-aresaying-about-cryptocurrencies (2017)

17. M. Hampl, Central banks, digital currencies and monetary policy in times of elastic money, available at: https://www.bis.org/review/r170720b.htm (2017)

18. S. Kryvoruchko, Financial Journal, 5, 120-129 (2018)

19. Chun Wei Wang, Economics Letters, 168, 21-24 (2018)

20. T. Ankenbrand, D. Bieri, Investment Management and Financial Innovations, 15(3), 169-181 (2018)

21. Won-Jun Lee, Seong-Tae Hong, Taeki Min, Journal of Distribution Science, 16, 47-56 (2018)

22. Yu. Liu, A. Tsyvinski, NBER Working Paper, 24877, available at: http://www.nber.org/papers/w24877 (2018)

23. Digitalisation and Financial Literacy, available at: http://www.oecd.org/finance/G20OECD-INFE-Policy-Guidance-Digitalisation-Financial-Literacy-2018.pdf (2018) 